ARTICLE

\title{
Electrochemically mediated carbon dioxide separation with quinone chemistry in salt-concentrated aqueous media
}

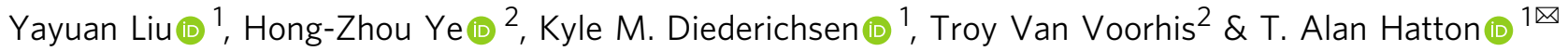

Carbon capture is essential for mitigating carbon dioxide emissions. Compared to conventional chemical scrubbing, electrochemically mediated carbon capture utilizing redox-active sorbents such as quinones is emerging as a more versatile and economical alternative. However, the practicality of such systems is hindered by the requirement of toxic, flammable organic electrolytes or often costly ionic liquids. Herein, we demonstrate that rationally designed aqueous electrolytes with high salt concentration can effectively resolve the incompatibility between aqueous environments and quinone electrochemistry for carbon capture, eliminating the safety, toxicity, and at least partially the cost concerns in previous studies. Salt-concentrated aqueous media also offer distinct advantages including extended electrochemical window, high carbon dioxide activity, significantly reduced evaporative loss and material dissolution, and importantly, greatly suppressed competing reactions including under simulated flue gas. Correspondingly, we achieve continuous carbon capture-release operations with outstanding capacity, stability, efficiency and electrokinetics, advancing electrochemical carbon separation further towards practical applications.

\footnotetext{
${ }^{1}$ Department of Chemical Engineering, Massachusetts Institute of Technology, Cambridge, MA 02139, USA. ${ }^{2}$ Department of Chemistry, Massachusetts

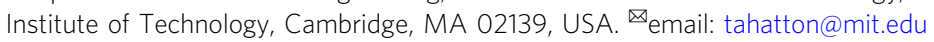


A nthropogenic carbon dioxide $\left(\mathrm{CO}_{2}\right)$ emissions present a serious challenge to our society. One of the foremost mitigation strategies involves carbon capture, particularly from large stationary emission sources, followed by sequestration or utilization ${ }^{1-5}$. The incumbent technology for carbon capture is wet chemical scrubbing, which utilizes aqueous amines to chemically absorb $\mathrm{CO}_{2}$ and subsequently release it by desorption via a temperature-swing process. However, this process is challenged by the substantial energy demand associated with the regeneration step, sorbent degradation, corrosion, environmental concerns and large footprint ${ }^{3,6}$. To this end, emerging materials such as water-lean solvents and porous solid sorbents have also been garnering widespread attention, with many showing promising capture properties ${ }^{7-10}$. Nevertheless, most of these $\mathrm{CO}_{2}$ storing materials are still reliant on high pressure and/or temperature-swing conditions during their operation cycles ${ }^{10}$. Electrochemically mediated separations offer a low-temperature, ambient-pressure alternative for carbon capture, representing a promising yet largely unchartered research area ${ }^{11-16}$. By being electrically driven, these systems can be controlled precisely to reduce energy losses, are modular and thus easy to implement in a variety of locations, and possess great adaptability to the multiscale nature of carbon capture.

In one form of electrochemically mediated carbon capture, redox-active organic compounds serve as $\mathrm{CO}_{2}$ carriers. Electrochemical reduction of these compounds generates nucleophiles with a high binding affinity towards electrophilic $\mathrm{CO}_{2}$ to afford stable sorbent- $\mathrm{CO}_{2}$ adducts; subsequently, the adducts can be oxidized to liberate pure $\mathrm{CO}_{2}$ while regenerating the sorbents ${ }^{13}$. To date, several classes of redox-active compounds have been explored, with quinoid species being the most representative example ${ }^{16-20}$. Quinones are a class of cyclic compounds containing two carbonyl groups in an unsaturated six-membered ring structure, which have been studied extensively for their key roles in biological electron transport as well as for promising applications in catalysis and energy storage ${ }^{21}$. They are versatile molecules with highly tailorable electrochemical properties through molecular engineering and can be synthesized from inexpensive commodity chemicals, which is favorable for large-scale applications ${ }^{22}$. Moreover, quinones as $\mathrm{CO}_{2}$ sorbents can have an appealingly high theoretical capacity of two $\mathrm{CO}_{2}$ equivalents per molecule, compared to conventional wet scrubbing which requires two equivalents of amine to capture one equivalent of $\mathrm{CO}_{2}$. Mizen and Wrighton ${ }^{23}$ first reported that electrogenerated 9,10-phenanthrenequinone dianion can chemically react with $\mathrm{CO}_{2}$ in homogeneous solutions to yield bis(carbonate), and further studies expanded the quinone chemistries for reversible $\mathrm{CO}_{2}$ capture-release $^{16-18,24,25}$. Despite this progress, electrochemically mediated $\mathrm{CO}_{2}$ separations still need to be operated using mainly flammable, toxic aprotic organic electrolytes, posing a great barrier toward practical implementation ${ }^{13}$. Recently, the relatively benign ionic liquids have also been explored as electrolytes for electrochemically mediated $\mathrm{CO}_{2}$ separations ${ }^{16,18}$. While it may not be a major issue for batch-based separation processes with lean electrolytes, the often-expensive ionic liquids can raise serious cost concerns in continuous-flow absorption systems where they are needed in excess for the dissolution of redox-active $\mathrm{CO}_{2}$ carriers.

An aqueous electrolyte is the ideal medium for large-scale electrochemical systems, offering distinct advantages in cost, safety, environmental benignity, and ease of device construction. Carbon capture via redox-active sorbents in aqueous electrolytes is, however, confronted with serious challenges. One critical limitation originates from the narrow electrochemical stability window of water, which is insufficient to support the reductive addition of $\mathrm{CO}_{2}$ to quinone molecules without incurring parasitic reactions (hydrogen evolution) ${ }^{23,26}$. Compared to aprotic solvents, aqueous media are complicated by the speciation of $\mathrm{CO}_{2}$ upon dissolution, which can undermine the activity of dissolved molecular $\mathrm{CO}_{2}$ given inappropriate solution $\mathrm{pH}^{15}$. Importantly, various competing reactions with reduced quinone molecules are expected in aqueous solutions, particularly protonation and ion association, hindering severely the kinetics and efficiency of carbon capture ${ }^{13,27-29}$. Finally, rapid evaporative loss is a longstanding concern when interfacing aqueous electrolytes with continuous gas flow, which can seriously compromise the service life of the electrochemical systems ${ }^{30}$.

Herein, by drawing inspiration from the recent breakthrough in salt-concentrated electrolytes for battery applications, we develop an aqueous electrolyte formulation that is fully compatible with quinone-mediated electrochemical carbon capture $26,30-32$. Saltconcentrated aqueous electrolytes, also known as "water-in-salt" electrolytes, are defined as those in which dissolved salt outnumbers water by both mass and volume ${ }^{26}$. In these solutions, the number of water molecules is insufficient to fully solvate the cations so that no free-state water exists, which can effectively suppress the activity of water molecules to extend the electrochemical stability window. By selecting appropriate salt species, desirable solution $\mathrm{pH}$ can be realized so that the total dissolved inorganic carbon is composed primarily of molecular $\mathrm{CO}_{2}$. It is worthwhile highlighting that, compared to their dilute counterpart, reduced quinone dianions are thermodynamically more reactive towards $\mathrm{CO}_{2}$ and less prone to competing reactions in salt-concentrated electrolytes, due to the modified dielectric environment. This results in enhanced carbon capture kinetics and capacity, as verified by both experiments and theoretical calculations. Additional technical superiorities, including high water retention under continuous gas sparging, and diminished dissolution of electrode-immobilized quinone molecules compared to organic electrolytes, are also observed when using our salt-concentrated electrolyte system. These multifold advantages enable the demonstration of quinone-meditated $\mathrm{CO}_{2}$ capturerelease with excellent capacity, kinetics, reversibility and stability in aqueous media, advancing electrochemical carbon separation further towards practical applications.

\section{Results}

Electrochemistry of quinone-mediated $\mathrm{CO}_{2}$ capture. Figure 1a shows the overall reaction of quinone-mediated $\mathrm{CO}_{2}$ capture and release, using anthraquinone (AQ) as an example. In aprotic media absent of electrophiles, quinones typically undergo two successive one-electron reductions (Fig. 1b, $\mathrm{N}_{2}$, and further illustrated in Supplementary Fig. 1), corresponding to the reversible formation of semiquinone radical anion $\left(\mathrm{AQ}^{{ }^{-}}\right)$and quinone dianion $\left(\mathrm{AQ}^{2-}\right)$. Interestingly, only a single reduction wave can be observed in the presence of electrophilic $\mathrm{CO}_{2}$ and the current nearly doubles with respect to that under $\mathrm{N}_{2}$ at the first reduction potential (Fig. 1b, $\mathrm{CO}_{2}$ ), indicating the interaction between reduced quinones and $\mathrm{CO}_{2}$. The complexation of $\mathrm{CO}_{2}$ with quinone is believed to proceed via an ECEC mechanism (E, electron transfer; $\mathrm{C}$, chemical reaction $)^{33}$. Namely, the reduction of AQ affords $\mathrm{AQ}^{\bullet-}$, which can react chemically with $\mathrm{CO}_{2}$ through nucleophilic addition; the resulting carbonate renders the quinone aromatic ring relatively neutral such that the second electron transfer can occur at nearly the same potential, generating one additional nucleophilic oxygen for $\mathrm{CO}_{2}$ attachment (Supplementary Fig. 2).

Similar electrochemical behavior is also commonly observed in protic electrolytes, where reduced quinones can react with protons to form hydroxyl groups via a two-electron reduction process $^{22}$. Correspondingly, one immediate hurdle when 
a<smiles>O=C1c2ccccc2C(=O)c2ccccc21</smiles>

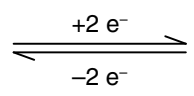<smiles>[O-]c1c2ccccc2c([O-])c2ccccc12</smiles>

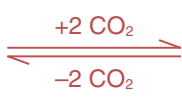<smiles>O=C([O-])Oc1c2ccccc2c(OC(=O)[O-])c2ccccc12</smiles>

b

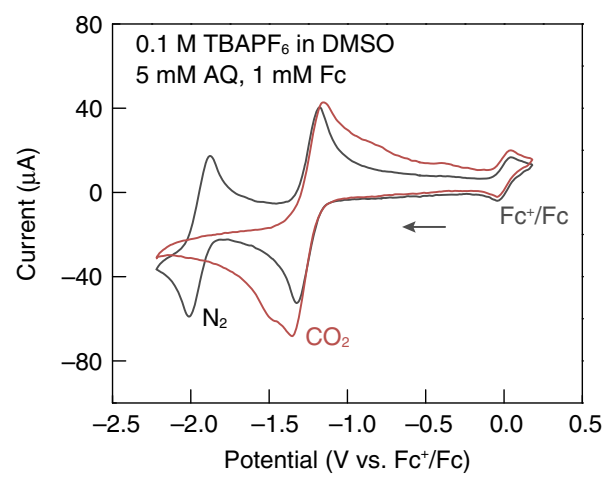

C

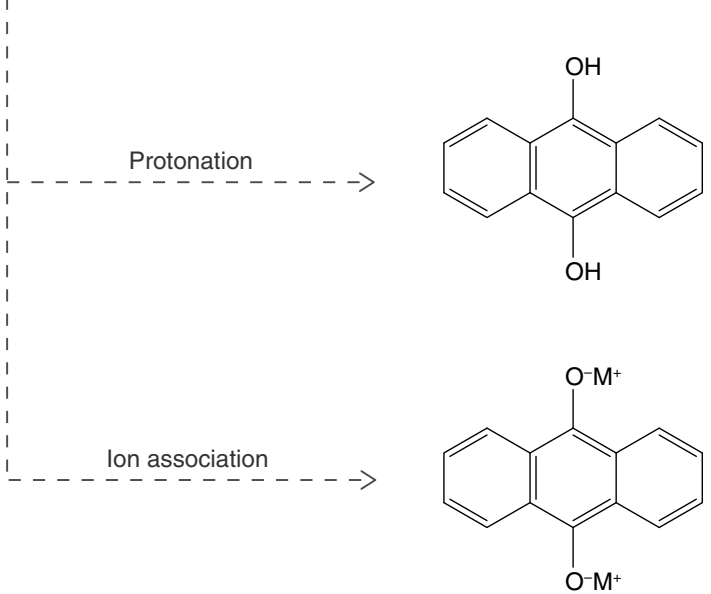

Fig. 1 Electrochemistry of quinone-mediated $\mathrm{CO}_{\mathbf{2}}$ capture. a The overall reductive addition reaction between $\mathrm{CO}_{2}$ and $A Q$. $\mathbf{b} C V$ of $A Q$ in an aprotic organic solvent with and without $\mathrm{CO}_{2}$. The $\mathrm{CV}$ scans were carried out in $5 \mathrm{mM} A Q$ in dimethyl sulfoxide (DMSO) with $0.1 \mathrm{M}$ tetrabutylammonium hexafluorophosphate $\left(\mathrm{TBAPF}_{6}\right)$ supporting salt. Glassy carbon was used as the working electrode, $\mathrm{Pt}$ wire as the counter electrode, $\mathrm{Ag}$ wire as a pseudoreference electrode, and $1 \mathrm{mM}$ ferrocene $(\mathrm{Fc})$ as an internal reference. The scan rate was $50 \mathrm{mV} \mathrm{s}^{-1}$. c Major competing reactions when carrying out quinone-mediated $\mathrm{CO}_{2}$ capture in aqueous media.

attempting to carry out quinone-mediated carbon capture in aqueous solutions is the rapid protonation of the reduced quinone molecules (Fig. 1c). For example, the rate constant for $\mathrm{AQ}^{2-}$ protonation was determined to be twice that of the reaction with $\mathrm{CO}_{2}$, such that full utilization of the carbon capture capacity is hardly achievable in the presence of proton donors ${ }^{27}$. Moreover, since both the tendency for quinone protonation and the activity of dissolved molecular $\mathrm{CO}_{2}$ increase with increasing solution acidity, an obvious dilemma is presented for aqueous electrolyte formulation. In addition to protonation through the formation of covalent bonds, cations in the supporting electrolyte can also stabilize quinone anions via Coulombic ion pairing (Fig. 1c), which may further reduce the driving force for $\mathrm{CO}_{2}$ complexation $^{29}$.

Aqueous electrolyte for quinone-mediated $\mathrm{CO}_{2}$ capture. The prerequisite for quinone-mediated $\mathrm{CO}_{2}$ capture-release in aqueous media is a wide electrochemical stability window of the electrolytes. Since only reduced quinones with sufficient electron density can undergo nucleophilic addition with molecular $\mathrm{CO}_{2}$, the formation of quinone- $\mathrm{CO}_{2}$ adducts generally occurs at potentials more negative than the reductive decomposition (hydrogen evolution reaction) potential of water ${ }^{33}$. Figure 2 a compares the cyclic voltammogram $(\mathrm{CV})$ of $\mathrm{AQ}$ under $\mathrm{CO}_{2}$ with the stability window of $1 \mathrm{~m}$ LiTFSI aqueous solution (where $\mathrm{m}$ is molality and LiTFSI represents lithium bis(trifluoromethanesulfonyl)imide). The reduction peak of AQ occurred at $\sim 0.88 \mathrm{~V}$ vs. $\mathrm{Ag} / \mathrm{AgCl}$, whereas the electrolyte started to decompose as early as $-0.81 \mathrm{~V}$ vs. Ag/ $\mathrm{AgCl}$ (defined as the potential where the current density reaches $\left.0.01 \mathrm{~mA} \mathrm{~cm}^{-2}\right)$.
Salt-concentrated electrolytes, recently gaining momentum in battery research, are proposed to offer an extended electrochemical stability window by eliminating the presence of freestate water through cation solvation $26,30-32$. For example, when the concentration of LiTFSI was increased to an ultrahigh level of $20 \mathrm{~m}$, the cathodic decomposition potential of the electrolyte was shifted to $-1.11 \mathrm{~V}$ vs. $\mathrm{Ag} / \mathrm{AgCl}$, which is sufficient to envelop the electrochemical capture and release of $\mathrm{CO}_{2}$ by quinones.

To ensure high solubility, salt species with stable and chargedelocalized anions, such as acetate, TFSI, trifluoromethanesulfonate, and bis(fluorosulfonyl)imide, are preferred when formulating water-in-salt electrolytes ${ }^{31}$. Nevertheless, not all of these salts are compatible with electrochemically mediated carbon capture. Gaseous $\mathrm{CO}_{2}$ has many possible transformations upon dissolution in water, yet only dissolved molecular $\mathrm{CO}_{2}(\mathrm{aq})$ is active towards complexation with reduced quinones (Fig. 2b). Therefore, electrolytes for electrochemically mediated carbon capture should have a $\mathrm{pH}$ value of less than 6 to ensure the dominance of $\mathrm{CO}_{2}(\mathrm{aq})^{15}$. The alkaline nature of acetate anion, being the conjugate base of a weak acid, precludes its use. For this proof of concept study, LiTFSI was selected as it is relatively well studied and satisfies this criterion, having a $\mathrm{pH}$ near 4 at both $1 \mathrm{~m}$ and $20 \mathrm{~m}$. The water-in-salt definition applies at concentrations above $5 \mathrm{~m}$, and at $20 \mathrm{~m}$, the ratio between $\mathrm{Li}^{+}$and $\mathrm{H}_{2} \mathrm{O}$ is only $\sim 1: 2.78$.

To verify the feasibility of quinone-mediated $\mathrm{CO}_{2}$ capture in salt-concentrated aqueous media, $\mathrm{CV}$ scans were conducted using poly(1,4-anthraquinone)-carbon nanotube (PAQ-CNT) composite under both $\mathrm{N}_{2}$ and $\mathrm{CO}_{2}$ atmospheres. PAQ was selected for the reduced solubility compared to its molecular counterpart. The immobilization of PAQ on CNT through $\pi-\pi$ interaction provides stable anchoring as well as fast electrical path 
a

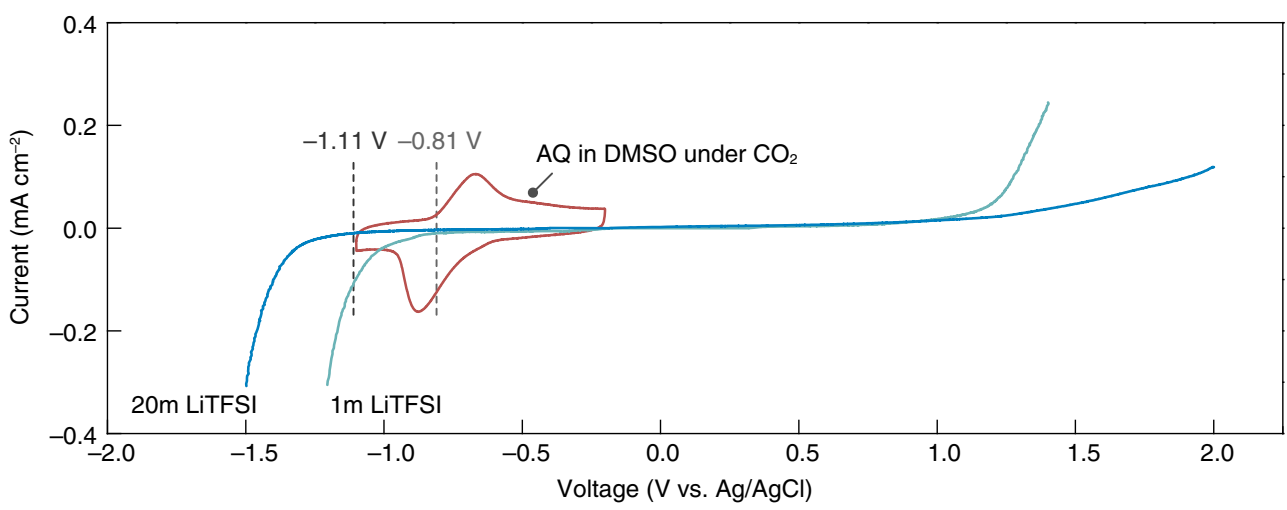

b

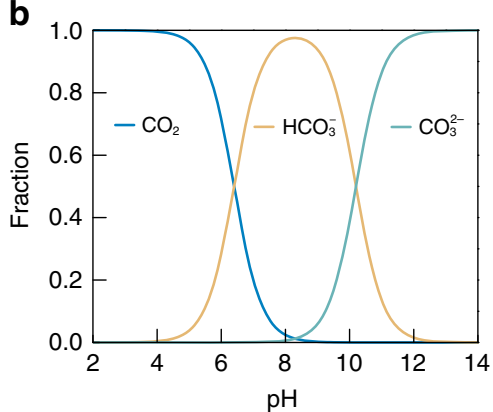

C

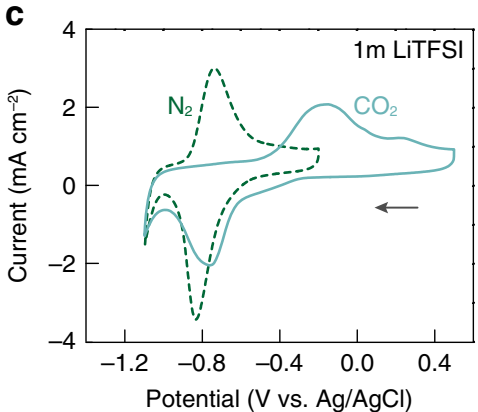

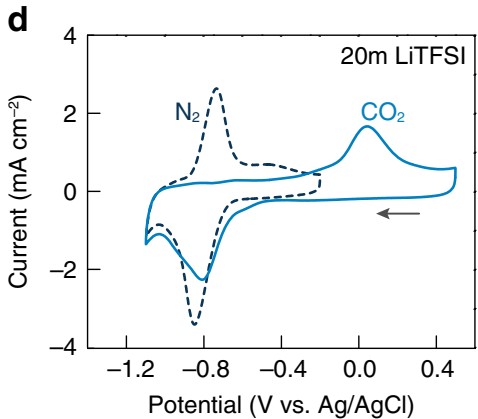

Fig. 2 Rational electrolyte formulation for quinone-mediated $\mathbf{C O}_{\mathbf{2}}$ capture in aqueous media. a Linear sweep voltammetry of 1 and $20 \mathrm{~m}$ LiTFSI aqueous electrolytes at a rate of $1 \mathrm{mV} \mathrm{s}^{-1}$, compared with the $\mathrm{CV}$ of $\mathrm{AQ}$ under $\mathrm{CO}_{2}$. Glassy carbon was used as the working electrode. Cathodic and anodic scans were performed separately and joined together afterwards. $\mathbf{b}$ The Bjerrum plot of the carbonic acid equilibrium as a function of the solution $\mathrm{pH}$ for an ideal solution at $25^{\circ} \mathrm{C}$. c, $\mathbf{d}$ CV of PAQ-CNT in $1 \mathrm{~m} \mathrm{LiTFSI} \mathrm{(c),} \mathrm{and} 20 \mathrm{~m} \mathrm{LiTFSI} \mathrm{(d),} \mathrm{under} \mathrm{N}_{2}$ (dashed line) and $\mathrm{CO}_{2}$ (solid line) at a rate $50 \mathrm{mV} \mathrm{s}{ }^{-1}$. PAQ was cast on glassy carbon at a loading of $0.042 \mathrm{mg} \mathrm{cm}^{-2}$. For $\mathbf{a}, \mathbf{c}, \mathbf{d}$, the electrochemical measurements were conducted with Pt wire as the counter electrode and $\mathrm{Ag} / \mathrm{AgCl}$ as the reference electrode. Source data are provided as a Source Data file.

(theoretical capacity $=260 \mathrm{mAh} \mathrm{g}^{-1}$, or $9.7 \mathrm{mmol} \mathrm{CO}_{2} \mathrm{~g}^{-1}$; structure shown in Supplementary Fig. 3$)^{34}$. This material has recently been successfully employed by our group to demonstrate electroswing-based $\mathrm{CO}_{2}$ separation in a parallel passage contactor configuration using an ionic liquid as the electrolyte ${ }^{16}$. Note that PAQ shows only a single, broad redox couple under $\mathrm{N}_{2}$ instead of two well-defined redox waves (as in the case of solution-phase molecular quinones), which can be ascribed to the slower electron exchange along the polymeric backbone and the hydrogen bonding effect of the aqueous media ${ }^{28,35}$. A substantial difference in electrochemical behavior can be seen in the presence of $\mathrm{CO}_{2}$ using LiTFSI-based electrolytes (Fig. 2c, d and at additional concentrations in Supplementary Fig. 4). The pronounced positive shift in the anodic peak is indicative of quinone bis (carbonate) formation, which requires extra driving force to be oxidized compared to quinone dianions. The successful formation of PAQ- $\mathrm{CO}_{2}$ adduct is also confirmed via X-ray photoelectron spectroscopy (XPS), where the C1s spectrum of PAQ reduced in $20 \mathrm{~m}$ LiTFSI under $\mathrm{CO}_{2}$ showed a close resemblance to that of PAQ- $\mathrm{CO}_{2}$ adduct obtained using a conventional organic electrolyte (Supplementary Fig. 5). Interestingly, the oxidation potential of the PAQ- $\mathrm{CO}_{2}$ adduct increases with increasing LiTFSI concentration. This is attributed to the stronger stabilization effect of $\mathrm{Li}^{+}$on the adduct at higher solution molalities as confirmed by the density functional theory (DFT) calculations (Supplementary Fig. 6 and Supplementary Note 1).

Minimized competing reactions in salt-concentrated electrolyte. To understand the effect of possible competing reactions on the reactivity of $\mathrm{PAQ}$ with $\mathrm{CO}_{2}$, Fig. 3a shows the CV scans of PAQ under $\mathrm{N}_{2}$ in $1 \mathrm{~m} \mathrm{NH}_{4} \mathrm{NO}_{3}$ ( $\mathrm{pH}$ adjusted to 4 with $\mathrm{HNO}_{3}$ ) and
LiTFSI electrolytes with different molalities $(\mathrm{pH} \sim 4$ ). It was previously established that protonation and cation association can stabilize reduced quinone species, inducing anodic shifts in the quinone reduction potential ${ }^{28}$. The reduction potential of PAQ in $1 \mathrm{~m} \mathrm{NH} \mathrm{NO}_{3}$ is significantly more positive than those in LiTFSIbased electrolytes. As $\mathrm{NH}_{4}{ }^{+}$is generally regarded as a bulky cation with low tendency for anion association, the large anodic shift in the reduction potential in $1 \mathrm{~m} \mathrm{NH} \mathrm{NH}_{4} \mathrm{NO}_{3}$ can only be ascribed to the protonation of reduced $\mathrm{PAQ}^{36}$. The protonation of reduced $\mathrm{PAQ}$ in $1 \mathrm{~m} \mathrm{NH} \mathrm{NHO}_{3}$ electrolyte severely undermines its potential carbon capture ability, which can be corroborated by ill-defined adduct oxidation peaks in $\mathrm{CV}$ scans under $\mathrm{CO}_{2}$ (Supplementary Fig. 7).

Protonation is greatly suppressed in LiTFSI-based electrolytes where $\mathrm{Li}^{+}$significantly outnumbers $\mathrm{H}^{+}$, rendering ion association the major competing reaction. Notably, though, both the onset and the peak potential of PAQ reduction shift towards more negative values with increasing LiTFSI concentrations (Fig. 3a), indicating weakened ion association. This is likely attributed to the dominance of associated salt species (contact ion pairs, CIP, and aggregates) in concentrated solutions as a result of incomplete cation solvation by water molecules ${ }^{26,31}$. To confirm this mechanistic interpretation, the free energy change $(\Delta G)$ for LiTFSI dissociation was calculated by DFT, where the increase in salt concentration can be modeled as a decrease in the dielectric constant of the electrolyte (Fig. 3b, Supplementary Fig. 8) ${ }^{37}$. The DFT results confirmed that the dissociation of LiTFSI becomes nonspontaneous $(\Delta G>0)$ above a certain concentration threshold, such that the kinetics of $\mathrm{Li}^{+}$-involved processes are necessarily slowed down in a salt-concentrated environment. More importantly, the thermodynamic driving force for quinone$\mathrm{CO}_{2}$ adduct formation, from both $\mathrm{AQ}^{2-}$ and $\mathrm{AQ}^{2-}$ complexed 
a
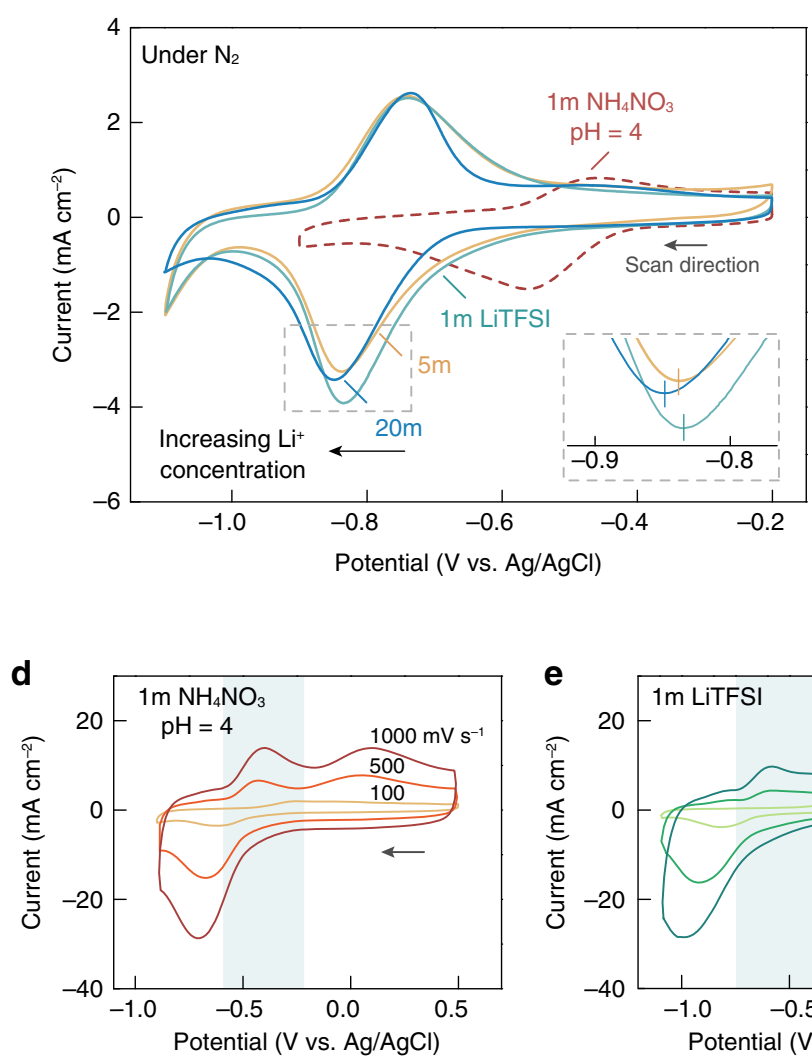
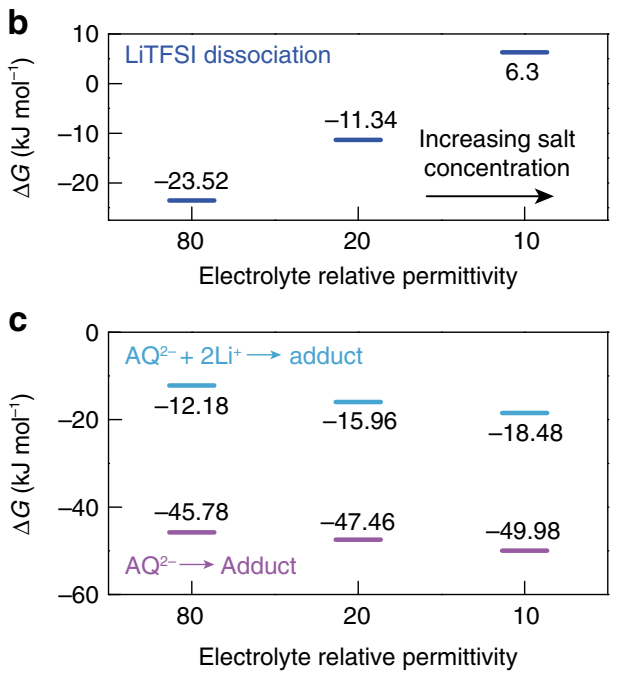
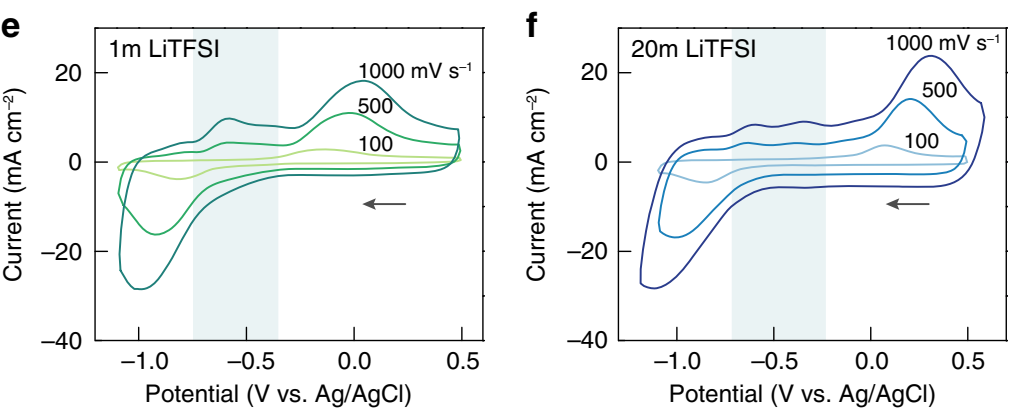

Fig. 3 Enhanced reactivity of $\mathbf{C O}_{\mathbf{2}}$ with quinones in salt-concentrated media. a CV of PAQ-CNT in $1 \mathrm{~m} \mathrm{NH} \mathrm{NNO}_{3}, 1,5$ and $20 \mathrm{~m}$ LiTFSI under $\mathrm{N}_{2}$. The scans were conducted at a rate $50 \mathrm{mV} \mathrm{s}^{-1}$. b The free energy change for LiTFSI dissociation at different electrolyte permittivities. Relative permittivities of 80 and 10 correspond to 1 and $20 \mathrm{~m} \mathrm{LiTFSI}$, respectively. The process becomes nonspontaneous at high LiTFSI concentrations. c The free energy change for quinone- $\mathrm{CO}_{2}$ adduct formation at different electrolyte permittivities, starting from both $\mathrm{AQ}^{2-}$ and $\mathrm{AQ}^{2-}$ complexed with $\mathrm{Li}^{+}$. The adduct formation becomes thermodynamically more favorable at higher LiTFSI concentrations. d-f CV of PAQ-CNT at different scan rates in $1 \mathrm{~m} \mathrm{NH}_{4} \mathrm{NO}_{3}(\mathbf{d}), 1 \mathrm{~m} \mathrm{LiTFSI}(\mathbf{e})$, and $20 \mathrm{~m} \mathrm{LiTFSI} \mathrm{(f)} \mathrm{under} \mathrm{CO}_{2}$. The shaded area corresponds to the oxidation of quinone dianions that are unreacted with $\mathrm{CO}_{2}$. For all the $\mathrm{CV}$ measurements, PAQ was cast on glassy carbon at a loading of $0.042 \mathrm{mg} \mathrm{cm}^{-2}$, Pt wire was used as the counter electrode, and $\mathrm{Ag} / \mathrm{AgCl}$ was used as the reference electrode. Source data are provided as a Source Data file.

with $\mathrm{Li}^{+}$, also increases with increasing electrolyte concentrations based on the DFT calculations (Fig. 3c).

This conclusion of enhanced reactivity of $\mathrm{CO}_{2}$ with quinones in salt-concentrated media can be seen experimentally by $\mathrm{CV}$ measurements under different scan rates (Fig. $3 \mathrm{~d}-\mathrm{f}$ ). Interestingly, besides the oxidation of quinone- $\mathrm{CO}_{2}$ adduct, an additional oxidation peak at less positive potential can be seen during fast scans (shaded area in Fig. $3 \mathrm{~d}-\mathrm{f}$ ), corresponding to the oxidation of quinone dianions that did not chemically react with $\mathrm{CO}_{2}$. Such a phenomenon is caused by the much more rapid electrochemical generation of reduced quinone species compared to the relatively slow $\mathrm{CO}_{2}$ transport and chemical reaction with reduced quinones, which inevitably becomes more pronounced with increasing scan rates. Quantitatively, while 100\% of the electrochemically generated quinone dianions reacted with $\mathrm{CO}_{2}$ at a scan rate of $100 \mathrm{mV} \mathrm{s}^{-1}$ in LiTFSI-based electrolytes, the value was only $77.5 \%$ when using $1 \mathrm{~m} \mathrm{NH}_{4} \mathrm{NO}_{3}$ likely due to the rapid protonation; and compared to $1 \mathrm{~m}$ LiTFSI, a higher percentage of adduct formation was observed in $20 \mathrm{~m}$ LiTFSI under all scan rates, thanks to the suppressed $\mathrm{Li}^{+}$association (Supplementary Fig. 9).

Therefore, it is clear from the above discussion that the reductive addition of $\mathrm{CO}_{2}$ to quinones is much less susceptible to competing reactions when carried out in salt-concentrated aqueous media, making them particularly attractive for quinonemediated carbon capture.
Physicochemical advantages of salt-concentrated electrolyte. In addition to being fully compatible with quinone electrochemistry and minimizing competing reactions, concentrated LiTFSI aqueous electrolytes also possess favorable physicochemical properties for the practical applications of electrochemically mediated carbon capture.

Firstly, salt-concentrated aqueous media demonstrate significantly enhanced resistance to evaporative loss compared to their dilute counterparts. Figure $4 \mathrm{a}$ plots the weight evolution of LiTFSI-based electrolytes under continuous, high-flow-rate gas sparging, where a stark contrast in water retention capability exists between the dilute (pure $\mathrm{H}_{2} \mathrm{O}, 1 \mathrm{~m}$ LiTFSI) and the concentrated (10 and 20m LiTFSI) electrolytes. While pure water suffered from $>56 \%$ weight loss (with respect to the initial electrolyte weight) after $168 \mathrm{~h}$ of gas purging, the value was merely $1.3 \%$ for $20 \mathrm{~m}$ LiTFSI. This unique feature effectively dispels the traditional concern of electrolyte dry-out when interfacing aqueous solutions with gas flows, rendering the potential quinone-mediated carbon capture system with flexibility in form factor and durability.

Secondly, salt-concentrated aqueous media containing no free water inhibit the dissolution of electroactive compounds immobilized on heterogeneous substrates, which is desirable for capacity retention during electrochemical cycling of many systems. Quinones, especially in their reduced forms, generally show high dissolution tendency in polar electrolytes $24,35,38$. Correspondingly, 
a
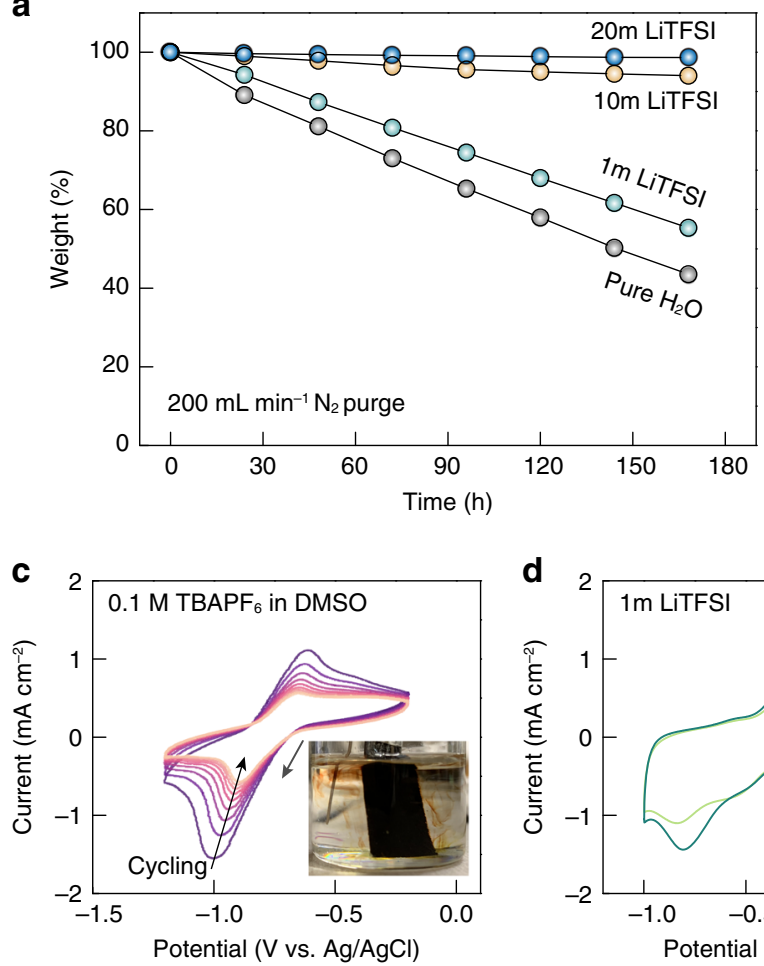

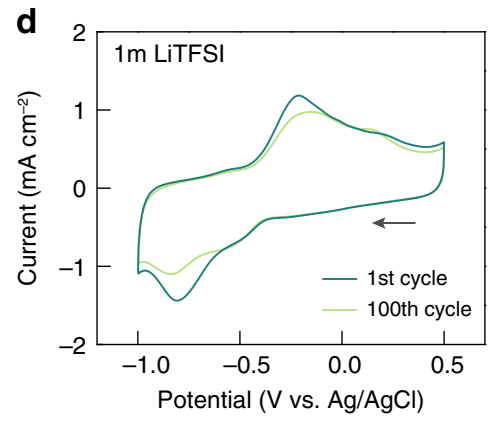

Fig. 4 Physicochemical advantages of salt-concentrated electrolytes for quinone-mediated $\mathbf{C O}_{\mathbf{2}}$ capture. a Weight retention curves of different electrolytes under constant $\mathrm{N}_{2}$ sparging at a high flow rate of $200 \mathrm{~mL} \mathrm{~min}^{-1}$. b Hydroquinone solubility in a representative organic solvent (DMSO), pure water and 20m LiTFSI aqueous electrolyte. c Multicycle CV scans of PAQ-CNT in 0.1 M TBAPF 6 DMSO electrolyte at a rate of $100 \mathrm{mV} \mathrm{s}^{-1}$. Inset shows the severe dissolution of PAQ (immobilized on carbon felt) into the electrolyte during electrochemical reduction in a DMSO-based electrolyte. $\mathbf{d}$, e The 1st and 100th CV scans of PAQ-CNT under $\mathrm{CO}_{2}$ in $1 \mathrm{~m} \mathrm{LiTFSI} \mathrm{(d)} \mathrm{and} 20 \mathrm{~m} \mathrm{LiTFSI} \mathrm{(e)} \mathrm{at} \mathrm{a} \mathrm{rate} \mathrm{of} 50 \mathrm{mV} \mathrm{s}^{-1}$. For all the CV measurements, PAQ was cast on glassy carbon, Pt wire was used as the counter electrode, and $\mathrm{Ag} / \mathrm{AgCl}$ was used as the reference electrode. Source data are provided as a Source Data file.

hydroquinone was selected as a probe molecule, and its solubility in various electrolytes was determined via UV-Vis spectrometry (Fig. 4b, Supplementary Figs. 10 and 11). A high hydroquinone solubility of $463 \mathrm{mg} \mathrm{mL}^{-1}$ was observed in dimethyl sulfoxide (DMSO) which is a representative organic solvent, resulting in visible PAQ dissolution and rapid capacity decay during electrochemical cycling (Fig. 4c and Supplementary Fig. 12). The solubility was decreased by fourfold when the organic solvent was replaced with water, yet the value remained significant. Therefore, $\sim 35 \%$ capacity loss of PAQ-CNT (decrease in cathodic peak intensity) was seen after $100 \mathrm{CV}$ cycles in $1 \mathrm{~m}$ LiTFSI (Fig. 4d). Noticeably, compared to that in pure water, the solubility of hydroquinone was reduced even further by $\sim 14$ times in $20 \mathrm{~m}$ LiTFSI. The greatly suppressed PAQ solubilization in salt-concentrated electrolytes, together with minimized side reactions, enabled impressive PAQ cycling stability ( $90 \%$ capacity retention after $100 \mathrm{CV}$ cycles, Fig. 4e).

Electrochemical cycling with high capacity and stability. To further evaluate the electrochemical performance of quinonemediated $\mathrm{CO}_{2}$ capture-release in salt-concentrated aqueous media, PAQ-CNT was immobilized on porous carbon felt substrates to increase both the active material mass loading and the electrode-electrolyte contact area. Fourier-transform infrared spectroscopy (FTIR) was employed to quantify the $\mathrm{CO}_{2}$ uptake capacity (Supplementary Fig. 13). Specifically, the PAQ-CNT electrode was electrochemically reduced to capture $\mathrm{CO}_{2}$ and was then placed in a sealed vial for thermal regeneration. After release, the headspace was sampled using an FTIR gas cell to determine the $\mathrm{CO}_{2}$ concentration. The thermal release capacity $\left(\mathrm{CO}_{2}\right.$ per gram of PAQ) was $\sim 4.7 \mathrm{mmol} \mathrm{g}^{-1}$ at $80^{\circ} \mathrm{C}$ and increased to $\sim 6.2 \mathrm{mmol} \mathrm{g}^{-1}$ at $120^{\circ} \mathrm{C}$. Nevertheless, as observed in previous studies ${ }^{24,25}$, thermal regeneration is less effective than the electrochemical route such that only $\sim 70 \%$ of the captured $\mathrm{CO}_{2}$ was liberated at $120^{\circ} \mathrm{C}$ (Supplementary Fig. 14). Considering this thermal release inefficiency, the carbon capture capacity of PAQ is $\sim 8.9 \mathrm{mmol} \mathrm{g}^{-1}$, which is close to its theoretical value of $9.7 \mathrm{mmol} \mathrm{g}^{-1}$.

Figure 5a shows the electrochemical $\mathrm{CO}_{2}$ capture-release voltage profiles at different cycling currents in $20 \mathrm{~m}$ LiTFSI electrolyte, where the PAQ electrode demonstrated excellent charge transfer kinetics. When cycled at a high current of $0.5 \mathrm{Ag}^{-1}$ (capture/ release in $\sim 30 \mathrm{~min}$ ), a carbon capture capacity of $\sim 8.4 \mathrm{mmol} \mathrm{g}^{-1}$ can be achieved ( $>86 \%$ of the theoretical value), which is higher than in the previously reported quinone-mediated carbon capture systems. Moreover, the value is on par with, if not higher than, the established amine-based processes $(\sim 8 \mathrm{mmol}$ per gram of amine, but $\sim 1-2$ mmol per gram of the total scrubbing absorbent $)^{24,39}$. Importantly, the capacity was only affected slightly with further increase in the cycling currents. For example, a working capacity of $\sim 6.6 \mathrm{mmol} \mathrm{g}^{-1}$ could still be obtained when the capture/release process was completed in only $\sim 6 \mathrm{~min}\left(2 \mathrm{Ag}^{-1}\right)$. The quinonemediated $\mathrm{CO}_{2}$ capture-release also demonstrated outstanding cycling stability and reversibility in salt-concentrated aqueous electrolytes (Fig. 5b). Minimal capacity loss can be observed after 150 cycles at a high current of $1.5 \mathrm{~A} \mathrm{~g}^{-1}$ (capture/release in $\sim 10 \mathrm{~min}$ ), with an average Coulombic efficiency (release capacity/ capture capacity) of near unity.

To gain deeper insights into the electrochemical $\mathrm{CO}_{2}$ capturerelease performance in a practical scenario, a prototypical membrane-based flow cell was constructed as shown schematically in Fig. 5 c. $\mathrm{LiFePO}_{4}$ was chosen as the counter electrode due to its well-established $\mathrm{Li}^{+}$intercalation-deintercalation electrochemistry 
a

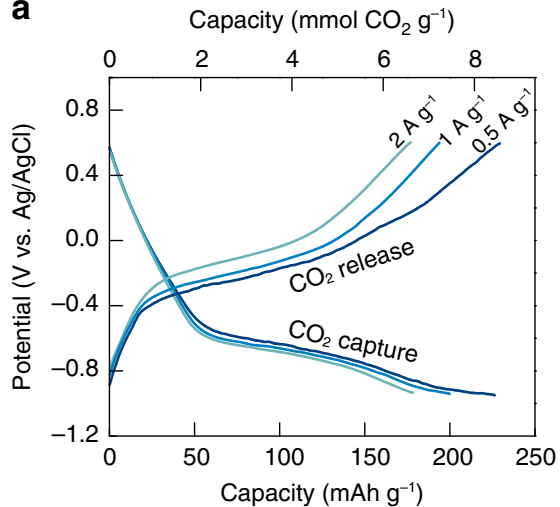

c

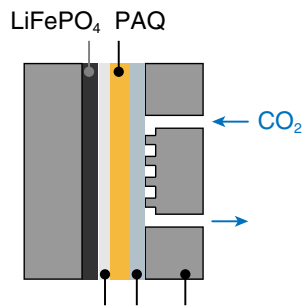

Glass fiber GDL Flow plate membrane b
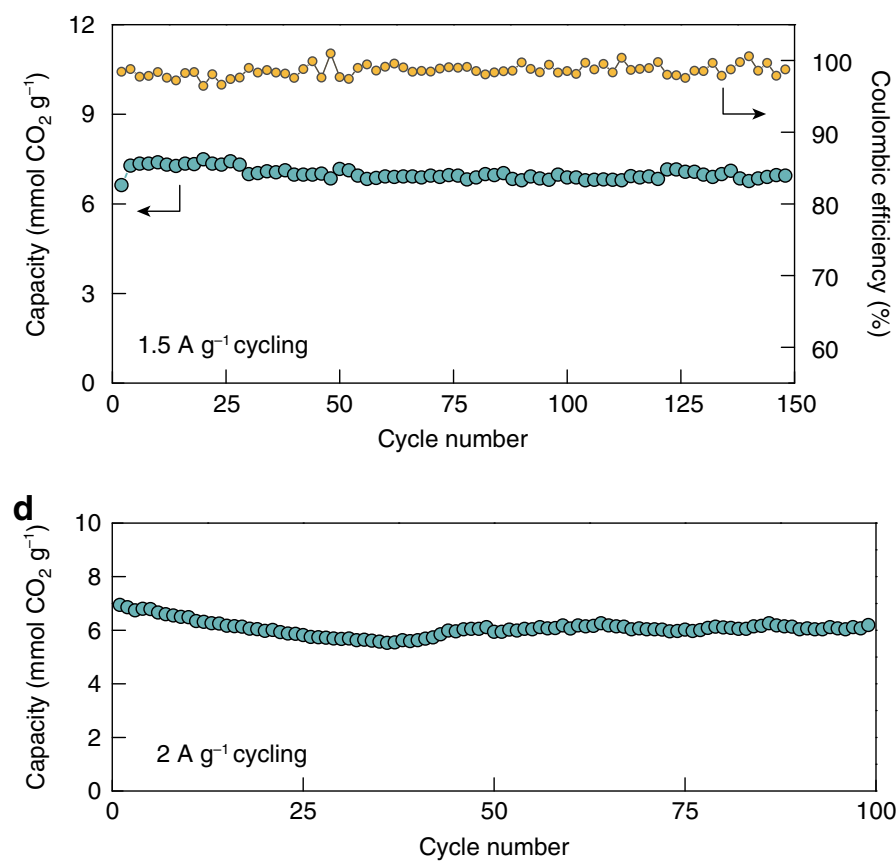

Fig. 5 Electrochemical carbon capture and release with high capacity and stability. a Electrochemical $\mathrm{CO}_{2}$ capture-release voltage profiles at different cycling current densities in $20 \mathrm{~m} \mathrm{LiTFSI.} \mathrm{b} \mathrm{Long-term} \mathrm{cycling} \mathrm{stability} \mathrm{and} \mathrm{Coulombic} \mathrm{efficiency} \mathrm{of} \mathrm{PAQ-CNT} \mathrm{in} 20 \mathrm{~m}$ LiTFSI at a high current of $1.5 \mathrm{Ag}^{-1}$ (capture/release in $\sim 10 \mathrm{~min}$ ). For (a) and (b), the mass loading of PAQ on carbon felt was $0.2 \mathrm{mg} \mathrm{cm}^{-2}$, LiFePO 4 on Al foil was used as the counter electrode, $\mathrm{Ag} / \mathrm{AgCl}$ was used as the reference electrode, and the measurements were carried out in a conventional single-compartment electrochemical cell. c Schematic illustrating the configuration of the membrane flow cell for $\mathrm{CO}_{2}$ capture-release. PAQ was immobilized on carbon felt at a mass loading of $1 \mathrm{mg} \mathrm{cm}^{-2}$, $\mathrm{LiFePO}_{4}$ coated on Al foil was used as the counter electrode, and the two electrodes were separated by an electrolyte-imbibed glass fiber membrane. A hydrophobic gas diffusion layer (GDL) was placed on one side of the PAQ electrode and interfaced with continuous $\mathrm{CO}_{2}$ flow. $\mathbf{d}$ Long-term cycling stability of the membrane flow cell in $20 \mathrm{~m} \mathrm{LiTFSI} \mathrm{at} \mathrm{a} \mathrm{cycling} \mathrm{current} \mathrm{of} 2 \mathrm{~A} \mathrm{~g}^{-1}$. For (b) and (d), PAQ reduction was carried out at constant current with a cut-off voltage of either $-0.95 \mathrm{~V}$ vs. $\mathrm{Ag} / \mathrm{AgCl}$ or $-1.4 \mathrm{~V}$ vs. $\mathrm{LiFePO}_{4}$. The oxidation of $\mathrm{PAQ}-\mathrm{CO}_{2}$ was conducted via the $\mathrm{CC} / \mathrm{CV}$ mode (constant current followed by constant voltage). The cut-off voltage for $\mathrm{CC}$ oxidation was either $0.2 \mathrm{~V}$ vs. $\mathrm{Ag} / \mathrm{AgCl}$ or $-0.1 \mathrm{~V}$ vs. $\mathrm{LiFePO}$; and $\mathrm{CV}$ oxidation was carried out until the current decayed to $10 \%$ of the CC oxidation current. Source data are provided as a Source Data file.

in aqueous environments $(\sim 0.42 \mathrm{~V}$ vs. $\mathrm{Ag} / \mathrm{AgCl}$ in $20 \mathrm{~m} \mathrm{LiTFSI})$ with high reversibility and excellent electrokinetics 39,40 . The capacity of the $\mathrm{LiFePO}_{4}$ electrode was at least four times in excess of that of the PAQ-CNT electrode to minimize the polarization from the counter electrode. The shortened ion-transport distance between the electrodes and the continuous delivery of gas-phase $\mathrm{CO}_{2}$ enabled high-current carbon capture-release with increased active material mass loading ${ }^{41}$. At a current of $2 \mathrm{~A} \mathrm{~g}^{-1}$ and a mass loading of $1 \mathrm{mg} \mathrm{cm}^{-2}$, the membrane flow cell demonstrated over 100 cycles of continuous carbon capture and release with good capacity retention (Fig. 5d), highlighting the outstanding capacity, stability, and reversibility of quinone-mediated carbon capture in salt-concentrated aqueous media.

$\mathrm{CO}_{2}$ response during electrochemical quinone cycling. Finally, we constructed a gas device to directly monitor the $\mathrm{CO}_{2}$ response in situ during quinone electrochemical cycling. The experimental setup is shown in Fig. 6a. Briefly, the PAQ- $\mathrm{LiFePO}_{4}$ electrochemical cell was mounted on a gasket with $\mathrm{CO}_{2}$ flowing on one side. Gaseous $\mathrm{CO}_{2}$ can dissolve into the electrolyte, transport through the electrochemical cell via diffusion and outgas into the $\mathrm{N}_{2}$ sweep stream on the other side. The permeated $\mathrm{CO}_{2}$ was then carried towards an in-line gas analyzer to determine the concentration. The detailed configuration of the gas cell is provided as Supplementary Fig. 15.

Figure $6 \mathrm{~b}$ shows the $\mathrm{CO}_{2}$ concentration response of the gas device during constant voltage capture and release (each capture/ release step was $10 \mathrm{~min}$, followed by a 10 -min rest), where a cyclic fluctuation of the permeated $\mathrm{CO}_{2}$ concentration can indeed be clearly observed. During capture, $\mathrm{CO}_{2}$ dissolved in the electrolyte was being actively consumed by the PAQ-CNT electrode, resulting in a continuous decrease in $\mathrm{CO}_{2}$ permeation; and the subsequent electrochemical oxidation of the $\mathrm{PAQ}-\mathrm{CO}_{2}$ adduct generated $\mathrm{CO}_{2}$ rapidly, leading to a sharp concentration spike until all the captured $\mathrm{CO}_{2}$ was released and the permeation restored to its background value (Fig. 6c). Note that the discrepancy between the onset of the electrochemical capture/ release and the $\mathrm{CO}_{2}$ signal response was due to system dispersion and the headspace volume of the flow chamber. Importantly, the consistent $\mathrm{CO}_{2}$ response over repeated electrochemical cycling further confirmed the stability of quinone chemistry for carbon capture in salt-concentrated aqueous media.

System testing in the presence of oxygen. The potential parasitic reaction (peroxide formation) between reduced quinones and molecular oxygen $\left(\mathrm{O}_{2}\right)$ present in the feed stream is generally regarded as a source of inefficiency in our described $\mathrm{CO}_{2}$ separation scheme ${ }^{13,17}$. Therefore, the electrochemical behavior of quinones in salt-concentrated aqueous electrolytes was further evaluated under mixed $\mathrm{CO}_{2} / \mathrm{O}_{2}$ conditions.

It is worth emphasizing that electrochemically mediated carbon capture operates in a mass transfer-limited regime. Therefore, we can take advantage of the substantial solubility difference between $\mathrm{O}_{2}$ and $\mathrm{CO}_{2}$ to reduce the efficiency loss. For 
a

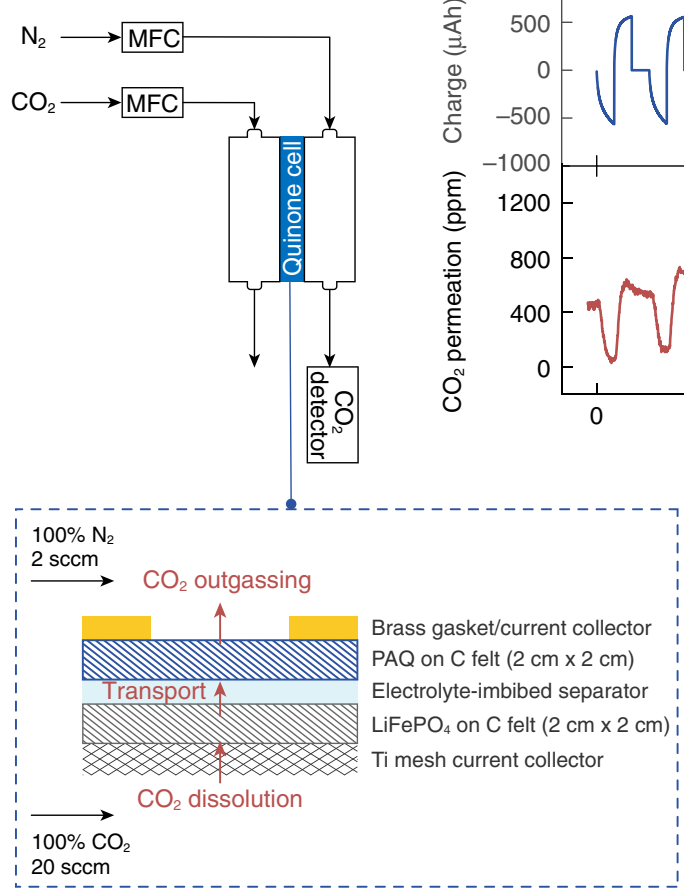

b

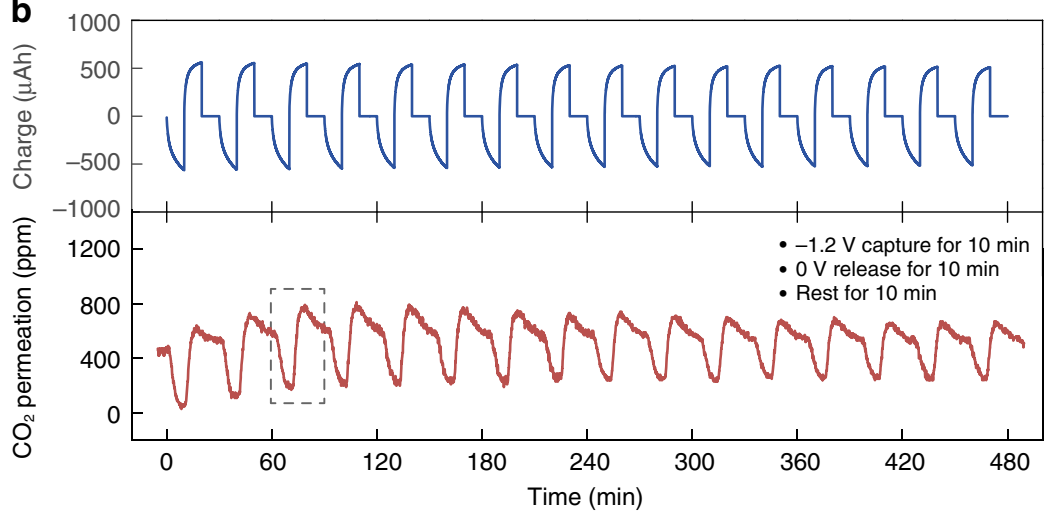

C

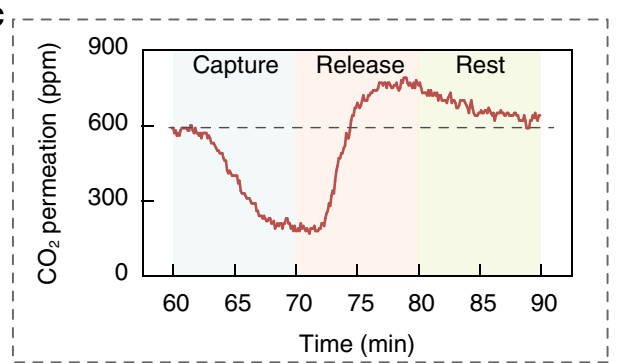

Fig. $6 \mathrm{CO}_{2}$ response during electrochemical quinone cycling. a Schematic illustrating the setup for the in situ measurement of $\mathrm{CO}_{2}$ response during $\mathrm{PAQ}$ cycling. MFC stands for mass flow controller. The electrochemical cell consisted of PAQ-CNT (PAQ $1 \mathrm{mg} \mathrm{cm}^{-2}$ ) and LiFePO $\mathrm{Lmg} \mathrm{cm}^{-2}$ ) electrodes cast on $50 \mu \mathrm{m}$-thick carbon felt $(2 \mathrm{~cm} \times 2 \mathrm{~cm}$ in area), and the two electrodes were separated by a $20 \mathrm{~m}$ LiTFSI-imbibed polypropylene separator. The electrochemical cell was mounted on a brass gasket with a $1 \mathrm{~cm}^{2}$ circular opening to the gas flow chamber, which also served as the current collector for the PAQ-CNT electrode. A titanium mesh with little impedance to gas flow was used as the current collector for $\mathrm{LiFePO}_{4}$. Pure $\mathrm{CO}_{2}$ flowed on one side of the electrochemical cell and pure $\mathrm{N}_{2}$ flowed on the other side to carry permeated $\mathrm{CO}_{2}$ to the in-line gas detector. The testing employed a "zero-gap" design where the electrochemical components were all in close contact, such that $\mathrm{CO}_{2}$ cross-over can only occur via dissolution-diffusion through the electrolyte. b $\mathrm{CO}_{2}$ permeation in response to the electrochemical cycling of the PAQ-LiFePO 4 cell, and the corresponding oxidation/reduction charge profiles. c Detailed $\mathrm{CO}_{2}$ permeation behavior during one capture-release cycle marked with a dashed line in (b). The cycling was conducted following a constant voltage capture-release protocol (capture at $-1.2 \mathrm{~V}$ for $10 \mathrm{~min}$, release at $0 \mathrm{~V}$ for $10 \mathrm{~min}$, rest $10 \mathrm{~min}$ ). Source data are provided as a Source Data file.

aqueous solutions at $25^{\circ} \mathrm{C}, \mathrm{CO}_{2}$ has $\sim 26$ times higher solubility than $\mathrm{O}_{2}$ under the same partial pressure ${ }^{42}$. While application for dilute scenarios such as direct air capture requires further investigation, we believe redox-active sorbents are competitive for carbon capture from stationary sources with relatively high $\mathrm{CO}_{2}$ partial pressure, such as carbon capture from power plants and large industrial processes (steel, cement and fertilizer plants, etc.), as well as in nonoxidizing environments (natural gas and biogas upgrading, etc.), which account for $\sim 60 \%$ of the total global greenhouse gas emissions ${ }^{43}$. Flue gas from coal-fired power plants typically contains $12-15 \% \mathrm{CO}_{2}$ and $3-5 \% \mathrm{O}_{2}$; in other industrial plants, the $\mathrm{CO}_{2}$ concentration in exhaust streams can be even higher (e.g. cement production $15-30 \%$, iron and steel $20-44 \%)^{43}$. Therefore, the limiting current involving $\mathrm{CO}_{2}$ can be two orders of magnitude higher than that involving $\mathrm{O}_{2}$ in our targeted carbon capture scenarios.

The potential of the $\mathrm{O}_{2} / \mathrm{O}_{2}{ }^{2-}$ redox couple in 1 and $20 \mathrm{~m}$ LiTFSI was studied using a glassy carbon electrode, which is known to catalyze the two-electron oxygen reduction reaction (ORR, Fig. 7a). The ORR onset potential was relatively negative for both cases, which can be attributed to the limited proton availability. The reaction product is likely to be $\mathrm{Li}_{2} \mathrm{O}_{2}$, which has been observed to be stable in salt-concentrated aqueous media due to significantly reduced $\mathrm{H}_{2} \mathrm{O}$ activity ${ }^{40}$, making it a poor oxidant. Importantly, compared to $1 \mathrm{~m} \mathrm{LiTFSI}$, the onset potential was $150 \mathrm{mV}$ more negative in $20 \mathrm{~m}$ LiTFSI together with reduced limiting current, further lowering the driving force for parasitic ORR. No obvious differences in CV can be observed for PAQ in 20m LiTFSI under $\mathrm{N}_{2}$ and $\mathrm{O}_{2}$ (Supplementary Fig. 16a). The ratio between the anodic and cathodic peak currents $\left(\mathrm{I}_{\mathrm{pa}} / \mathrm{I}_{\mathrm{pc}}\right)$ is 0.98 and 0.97 under $\mathrm{N}_{2}$ and $\mathrm{O}_{2}$ respectively, confirming the relatively low sensitivity of reduced PAQ towards $\mathrm{O}_{2}$ in $20 \mathrm{~m}$ LiTFSI. Redox-active sorbents with higher reduction potentials (e.g. 1,4naphthoquinone, NQ, Supplementary Fig. 16b) can also be chosen to minimize side reactions.

Importantly, the quinone- $\mathrm{CO}_{2}$ adducts are much more stable against oxidation compared to the corresponding quinone dianions due to their increased oxidation potential and, as described previously, the oxidation potential also increases with increasing LiTFSI concentration (Fig. 2c, $d$ and Supplementary Fig. 6). As shown in Fig. $7 \mathrm{~b}$, the onset potential for PAQ- $\mathrm{CO}_{2}$ oxidation (ca. $-0.26 \mathrm{~V}$ vs. $\mathrm{Ag} / \mathrm{AgCl}$ ) can become more positive than the onset potential for ORR ( $\mathrm{ca} .-0.43 \mathrm{~V}$ vs. $\mathrm{Ag} / \mathrm{AgCl}$ ) in $20 \mathrm{~m}$ LiTFSI, such that the adduct will be much less prone to react with $\mathrm{O}_{2}$ in salt-concentrated aqueous media. This is not the case at low salt concentration. Adopting quinones with higher redox potentials can further increase the potential difference for even more stable adducts (Supplementary Fig. 17).

To further investigate the stability of the quinone- $\mathrm{CO}_{2}$ adduct, we quantified the degree of PAQ- $\mathrm{CO}_{2}$ oxidation in the presence of $\mathrm{O}_{2}$. Specifically, the PAQ electrodes were first fully reduced under $\mathrm{CO}_{2}$ and were then allowed to rest in the presence of different concentrations of $\mathrm{O}_{2}$, after which the electrodes were reduced again to quantify the capacity loss (Fig. 7c and Supplementary Fig. 18). Merely $9.4 \%$ of the adducts were oxidized after resting in air for $15 \mathrm{~min}$, which is the typical capture-release time scale for 

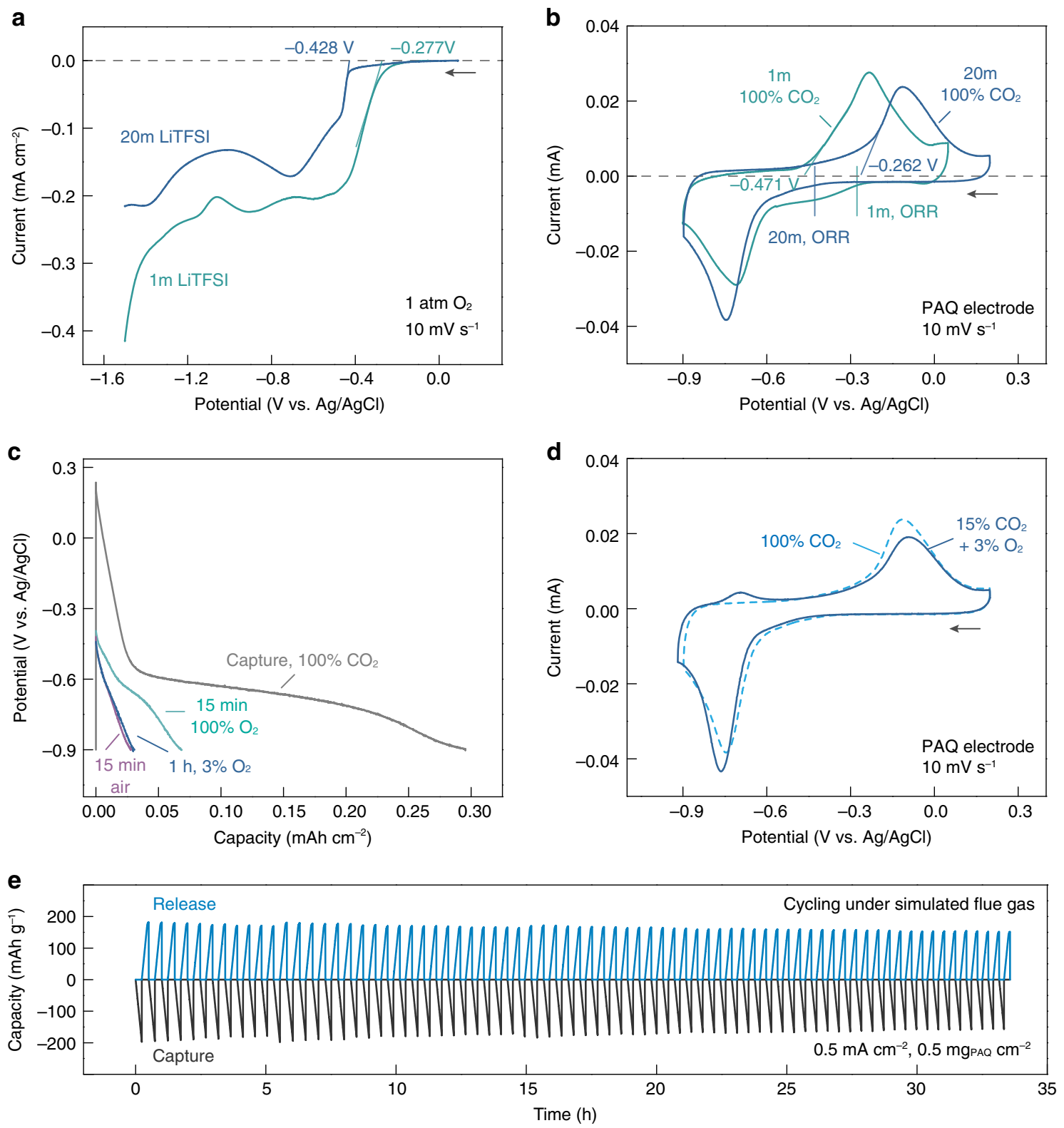

Fig. 7 Electrochemical $\mathbf{C O}_{\mathbf{2}}$ capture-release in the presence of $\mathbf{O}_{\mathbf{2}}$. a Linear sweep voltammograms of 1 and $20 \mathrm{~m} \mathrm{LiTFSI} \mathrm{saturated} \mathrm{with} \mathrm{O}_{2}$ measured with a glassy carbon electrode at a rate of $10 \mathrm{mV} \mathrm{s}^{-1}$. b Comparison between the oxidation potential of $\mathrm{PAQ}-\mathrm{CO}_{2}$ (with onset potential noted) and the ORR potential (from a) in 1 and $20 \mathrm{~m} \mathrm{LiTFSI}$. c Reduction profiles of PAQ under $\mathrm{CO}_{2}$ in $20 \mathrm{~m} \mathrm{LiTFSI}$ and of the same electrode after being rested in $100 \%$ O $(15 \mathrm{~min})$, air $(15 \mathrm{~min})$ and $3 \% \mathrm{O}_{2}(1 \mathrm{~h})$, respectively. The reductions were carried out at a current density of $0.5 \mathrm{~mA} \mathrm{~cm}{ }^{-2}$ and the PAQ was immobilized on carbon felt at a mass loading of $1.2 \mathrm{mg} \mathrm{cm}^{-2}$. d CV scans of PAQ under pure $\mathrm{CO}_{2}$ and simulated flue gas in $20 \mathrm{~m}$ LiTFSI. The ratio between the total anodic and cathodic capacities was $87.3 \%$ and $80.7 \%$ for pure $\mathrm{CO}_{2}$ and simulated flue gas, respectively. The additional anodic peak observed under simulated flue gas corresponds to the oxidation of quinone anions that did not react with $\mathrm{CO}_{2}$ due to mass transport limitation. For (b) and (d), the $\mathrm{CV}$ scans were conducted at a rate of $10 \mathrm{mV} \mathrm{s}^{-1}$ with $1.5 \mu \mathrm{g}$ PAQ loaded on the glassy carbon electrode. e The capture-release capacity of PAQ during continuous cycling under simulated flue gas. The cycling was carried out in the membrane flow cell configuration at a current density of $0.5 \mathrm{~mA} \mathrm{~cm}-2$ and a PAQ mass loading of $0.5 \mathrm{mg} \mathrm{cm}^{-2}$ (immobilized on carbon felt). CC capture and CC/CV release protocol was adopted with the cut-off voltage being -1.35 and $-0.1 \mathrm{~V}$, respectively. Each capture/release step has a time scale of $\sim 15 \mathrm{~min}$. Source data are provided as a Source Data file.

our electro-swing $\mathrm{CO}_{2}$ separation; and even when rested in pure $\mathrm{O}_{2}$, only $23.2 \%$ of the capacity was lost after $15 \mathrm{~min}$. Moreover, in the presence of $3 \% \mathrm{O}_{2}$, which is the typical concentration in coalfired power plant flue gas, $90 \%$ of the capacity was maintained after $1 \mathrm{~h}$. While further improvements will be required for full practical implementation, these results demonstrate a promising pathway to minimizing the effects of oxygen on quinone capture processes.

Figure $7 \mathrm{~d}$ shows the $\mathrm{CV}$ scans of PAQ under pure $\mathrm{CO}_{2}$ and simulated flue gas $\left(15 \% \mathrm{CO}_{2}\right.$ with $\left.3 \% \mathrm{O}_{2}\right)$. To compare the efficiency under the two scenarios, we calculated the ratio between the total anodic and cathodic capacities $\left(Q_{a} / Q_{c}\right)$. At a scan rate of $10 \mathrm{mV} \mathrm{s}^{-1}$, the value was $87.3 \%$ under pure $\mathrm{CO}_{2}$ and decreased slightly to $80.7 \%$ under simulated flue gas. At an even slower scan rate of $5 \mathrm{mV} \mathrm{s}^{-1}$ to ensure the complete reaction between PAQ dianions and $\mathrm{CO}_{2}$, a high $Q_{\mathrm{a}} / Q_{\mathrm{c}}$ of $83.6 \%$ can be achieved (Supplementary Fig. 19a). Replacing PAQ with NQ afforded further improved efficiency (Supplementary Fig. 19b). When constant current $\mathrm{CO}_{2}$ capture-release cycling was conducted under simulated flue gas in the membrane flow cell 
configuration, high capacity cycling with good stability was still realized (Fig. 7e) with only moderately compromised efficiency (the average Coulombic efficiency over 75 cycles was $95.5 \%$, as shown in Supplementary Fig. 20). The electrical energy consumption of this capture-release process was calculated to be $\sim 56 \mathrm{~kJ} \mathrm{~mol}^{-1} \mathrm{CO}_{2}$ (Supplementary Note 2), which is on par with other carbon capture systems ${ }^{44}$. A more detailed energetic analysis of quinone-mediated carbon capture in a conventional electrolyte can be found in a recent literature ${ }^{16}$. The process energetics can be further improved with engineering optimization. With the data above, we believe our proposed system of electrochemically mediated carbon capture in salt-concentrated aqueous media can indeed be of practical significance for carbon capture from point sources.

\section{Discussion}

In this work, we investigated the feasibility of employing saltconcentrated aqueous electrolytes for electrochemically mediated $\mathrm{CO}_{2}$ separation using quinone chemistry. By rationally designing the electrolyte formulation, salt-concentrated aqueous electrolytes can offer an extended electrochemical stability window, high $\mathrm{CO}_{2}$ activity, as well as significantly reduced active material dissolution and evaporative loss. Importantly, reduced quinone species are much less susceptible to competing reactions such as protonation and ion association in salt-concentrated media compared to their dilute counterparts due to the modified dielectric environment, which is highly desirable for quinone- $\mathrm{CO}_{2}$ adduct formation. As a result, high capacity $\mathrm{CO}_{2}$ capture-release cycling with excellent electrokinetics, efficiency and stability was demonstrated in both conventional single-compartment electrochemical cell and prototypical membrane-based flow cell. When tested using simulated flue gas, our proposed system maintained good performance metrics and competitive system energetics. The proved advantages of saltconcentrated aqueous electrolytes are also transferable to other types of redox-active molecular $\mathrm{CO}_{2}$ sorbents. The material design demonstrated through these results advances the practicality of electrochemically mediated carbon capture with redox-active molecular $\mathrm{CO}_{2}$ sorbents broadly, given that the inherent advantages are not limited to our example quinone chemistry.

\section{Methods}

Materials. The electrolytes were prepared by dissolving the corresponding salts, lithium bis(trifluoromethanesulfonyl)imide (Solvay), and/or tetrabutylammonium hexafluorophosphate (Sigma-Aldrich) in water and/or DMSO (Sigma-Aldrich). Ferrocene and anthraquinone were purchased from Sigma-Aldrich.

Synthesis of the PAQ-CNT electrode. PAQ was synthesized following a previously reported procedure ${ }^{32}$. To obtain the PAQ-CNT composite, PAQ was dissolved in chloroform $\left(1 \mathrm{mg} \mathrm{mL}^{-1}\right)$ using a probe sonicator at $5{ }^{\circ} \mathrm{C}$ (Cole-Parmer Ultrasonic Processor, pulser mode: on $5 \mathrm{~s}$, off $3 \mathrm{~s}, 60 \%$ amplitude). Subsequently, $\mathrm{CNT}$ was added into the solution $\left(1 \mathrm{mg} \mathrm{mL}^{-1}\right)$, and the mixture was sonicated for another $20 \mathrm{~min}$ to afford a homogeneous dispersion. The PAQ-CNT ink was then cast on either glassy carbon electrode (Ø $3 \mathrm{~mm}, \mathrm{BASi}$ ) or $50 \mu \mathrm{m}$ carbon felt (Fibre Glast Carbon Fiber Veil).

Characterizations. SEM images were taken with a Zeiss SUPRA 55-VP scanning electron microscope. XPS analysis was obtained on a Thermo Scientific K-Alpha+ XPS equipped with $\mathrm{Al}(\mathrm{Ka})$ source with a spot size of $400 \mu \mathrm{m}$. High-resolution spectra were collected with a step size of $0.1 \mathrm{eV}$ and an accumulation of ten scans. Hydroquinone solubility was determined based on UV-Vis absorption spectra (Ocean Optics). The evaporative loss rate of the electrolytes was measured by monitoring their weight change under constant $\mathrm{N}_{2}$ purging. In each experiment, $5 \mathrm{~mL}$ electrolyte was sealed in a $20-\mathrm{mL}$ glass vial with septum cap, which was equipped with a $21 \mathrm{G}$ needle inlet and a $21 \mathrm{G}$ needle outlet. Pure $\mathrm{N}_{2}$ gas was bubbled directly into the electrolyte through the needle inlet at a flow rate of $200 \mathrm{~mL} \mathrm{~min}^{-1}$.

$\mathrm{CO}_{2}$ capture/release quantification by FTIR spectroscopy. A Nicolet $8700 \mathrm{FTIR}$ spectrometer (Thermo Scientific) and a $100-\mathrm{mm}$ short-path IR gas cell (Pike Technologies, septum-sealed) were employed for the quantification of $\mathrm{CO}_{2}$ capture/release by PAQ. The spectrometer chamber was under high-flow-rate $\mathrm{N}_{2}$ purging during the measurements to avoid interference from atmospheric $\mathrm{CO}_{2}$. The calibration curve was made by injecting (Hamilton 1700 series gastight syringes with $30 \mathrm{G}$ needle) defined amounts of pure $\mathrm{CO}_{2}$ into the $\mathrm{N}_{2}$ flushed IR gas cell and measuring the integrated area of the two $\mathrm{CO}_{2}$ asymmetric stretching bands in absorbance mode $\left(2335\right.$ and $\left.2360 \mathrm{~cm}^{-1}\right)$. For the quantification, $\mathrm{CO}_{2}$ was captured electrochemically by PAQ $(0.25 \mathrm{mg}$ on carbon felt $)$ via two $\mathrm{CV}$ reduction cycles at a slow scan rate of $5 \mathrm{mV} \mathrm{s}^{-1}$. The electrode was then removed from the electrochemical cell, thoroughly dried with paper towel, and sealed in a 2- $\mathrm{mL} \mathrm{N}_{2}$ flushed glass vial with septum cap (Agilent autosampler vial). Thermal release instead of electrochemical release was chosen to avoid the outgassing of physically dissolved $\mathrm{CO}_{2}$ from the electrolyte in the case of electrochemical release, which can compromise the quantification accuracy. After 30-min thermal release on a hotplate, $250 \mu \mathrm{L}$ headspace gas was taken and injected into the $\mathrm{N}_{2}$ flushed IR gas cell to obtain the corresponding IR spectrum. The capture and release experiments were done in triplets at each thermal release temperature.

Electrochemical measurements. All the electrochemical measurements were conducted using a VersaSTAT4 potentiostat (Princeton Applied Research) in a conventional single-compartment electrolytic cell (BASi), unless otherwise specified. The glassy carbon electrode used in this study has a diameter of $3 \mathrm{~mm}$ and was polished before each measurement. The $\mathrm{LiFePO}_{4}$ on $\mathrm{Al}$ foil electrode was purchased from MTI Corp. (single side coated, active material loading $12 \mathrm{~g} \mathrm{~cm}^{-2}$ ). The $\mathrm{LiFePO}_{4}$ on carbon felt electrode was prepared by mixing 95\% LFP (MTI Corp.), $2.5 \%$ carbon black (Super P, MTI Corp.) and 2.5\% polyvinylidene fluoride (SigmaAldrich) in $N$-methylpyrrolidinone followed by casting on $50 \mu \mathrm{m}$ carbon felt (mass loading $8 \mathrm{mg} \mathrm{cm}^{-2}$ ). For the construction of the PAQ-LiFePO ${ }_{4}$ membrane flow cell, PAQ-CNT was immobilized on $50 \mu \mathrm{m}$ carbon felt at a mass loading of $1 \mathrm{mg}$ $\mathrm{cm}^{-2}$ and $\mathrm{LiFePO}_{4}$ on $\mathrm{Al}$ foil was used as the counter electrode. Both electrodes were $2 \mathrm{~cm} \times 2 \mathrm{~cm}$ in area and were separated by an electrolyte-imbibed glass fiber membrane (MilliporeSigma). A hydrophobic gas diffusion layer (Toray carbon paper, PTFE treated, TGP-H-60) was placed on one side of the PAQ electrode to interface with continuous $\mathrm{CO}_{2}$ flow. The reduction of PAQ was conducted with a cut-off voltage of either $-0.95 \mathrm{~V}$ vs. $\mathrm{Ag} / \mathrm{AgCl}$ or $-1.4 \mathrm{~V}$ vs. $\mathrm{LiFePO}_{4}$ counter electrode to prevent the possible TFSI ${ }^{-}$decomposition. The oxidation of $\mathrm{PAQ}-\mathrm{CO}_{2}$ was conducted via the $\mathrm{CC} / \mathrm{CV}$ mode (constant current followed by constant voltage). The cut-off voltage for CC oxidation was either $0.2 \mathrm{~V} \mathrm{vs.} \mathrm{Ag} / \mathrm{AgCl}$ or $-0.1 \mathrm{~V}$ vs $\mathrm{LiFePO}_{4} ; \mathrm{CV}$ oxidation was carried out until the current decayed to $10 \%$ of the CC oxidation current.

In situ gas cell measurements. Measurements on the $\mathrm{CO}_{2}$ permeation response during quinone cycling were conducted using a house-machined device consisting of two gas flow chambers separated by the PAQ- $\mathrm{LiFePO}_{4}$ electrochemical cell, all held together with rubber gaskets and screws (detailed gas cell configuration is shown as Supplementary Fig. 16). Both PAQ-CNT $\left(1 \mathrm{mg} \mathrm{cm}^{-2}\right)$ and $\mathrm{LiFePO}_{4}\left(8 \mathrm{mg} \mathrm{cm}{ }^{-2}\right)$ were cast on $50 \mu \mathrm{m}$ carbon felt, and the electrode area was $2 \mathrm{~cm} \times 2 \mathrm{~cm}$. The two electrodes were separated with a $25 \mu \mathrm{m}$ polypropylene separator (Celgard 3501) infused with 20m LiTFSI electrolyte. The PAQ-LiFePO electrochemical cell was mounted on a brass gasket holder with a $1 \mathrm{~cm}^{2}$ circular opening, and the edges of the electrochemical cell were sealed to block gas-phase $\mathrm{CO}_{2}$ transport between the two flow chambers. The brass gasket also served as the current collector for the PAQ-CNT electrode, and a titanium mesh was used as the current collector for the $\mathrm{LiFePO}_{4}$ electrode. The testing employed a "zerogap" design where the electrochemical components were all in close contact, such that $\mathrm{CO}_{2}$ cross-over can only occur via dissolution-diffusion through the electrolyte. During operation, $\mathrm{CO}_{2}$ flowed through one gas chamber and $\mathrm{N}_{2}$ sweep gas flowed through the other. The concentration of $\mathrm{CO}_{2}$ in the $\mathrm{N}_{2}$ stream was measured with an in-line $\mathrm{CO}_{2}$ sensor (ExplorIR ${ }^{\oplus} \mathrm{W} 20 \% \mathrm{CO}_{2}$ sensor). The sensor has a measurement range of $0-20 \% \mathrm{CO}_{2}$ and an accuracy of $\pm 70 \mathrm{ppm}$. The electrochemical cycling followed a constant voltage protocol. For each capturerelease cycle, the cell was first held at $-1.2 \mathrm{~V}$ for $10 \mathrm{~min}$ to capture $\mathrm{CO}_{2}$, followed by release at $0 \mathrm{~V}$ for $10 \mathrm{~min}$ and a $10-\mathrm{min}$ rest.

\section{Data availability}

The datasets generated during and/or analyzed during the current study are available from the corresponding author on reasonable request. The source data underlying Figs. 2a, c, d, 3a, d-f, 4a, c-e, 5a, b, d, 6b, 7a-e and Supplementary Figs. 17, 19, 20 and 22 are provided as a Source Data file.

Received: 7 January 2020; Accepted: 17 April 2020; Published online: 08 May 2020

\section{References}

1. Chu, S. Carbon capture and sequestration. Science 325, 1599 (2009).

2. Haszeldine, R. S. Carbon capture and storage: how green can black be? Science 325, 1647-1652 (2009).

3. Rochelle, G. T. Amine scrubbing for $\mathrm{CO}_{2}$ capture. Science 325, 1652-1654 (2009). 
4. Keith, D. W., Holmes, G., St. Angelo, D. \& Heidel, K. A process for capturing $\mathrm{CO}_{2}$ from the atmosphere. Joule 2, 1573-1594 (2018).

5. Dubois, M. R. \& Dubois, D. L. Development of molecular electrocatalysts for $\mathrm{CO}_{2}$ reduction and $\mathrm{H}_{2}$ production/oxidation. Acc. Chem. Res. 42, 1974-1982 (2009).

6. Vasudevan, S. et al. Energy penalty estimates for $\mathrm{CO}_{2}$ capture: comparison between fuel types and capture-combustion modes. Energy 103, 709-714 (2016).

7. Shi, X. et al. Sorbents for direct capture of $\mathrm{CO}_{2}$ from ambient air. Angew. Chem. Int. Ed. https://doi.org/10.1002/anie.201906756 (2019).

8. Heldebrant, D. J. et al. Water-lean solvents for post-combustion $\mathrm{CO}_{2}$ capture: fundamentals, uncertainties, opportunities, and outlook. Chem. Rev. 117, 9594-9624 (2017).

9. Lin, K. -Y. A. \& Park, A. -H. A. Effects of bonding types and functional groups on $\mathrm{CO}_{2}$ capture using novel multiphase systems of liquid-like nanoparticle organic hybrid materials. Environ. Sci. Technol. 45, 6633-6639 (2011).

10. Sumida, K. et al. Carbon dioxide capture in metal-organic frameworks. Chem. Rev. 112, 724-781 (2012).

11. Terry, P. A., Walis, H. J., Noble, R. D. \& Koval, C. A. Electrochemically modulated complexation process for gas removal and concentration. AIChE J. 41, 2556-2564 (1995).

12. Terry, P. A., Noble, R. D., Swanson, D. \& Koval, C. A. Electrochemically modulated complexation process for ethylene/ethane separation. AIChE J. 43, 1709-1716 (1997).

13. Rheinhardt, J. H., Singh, P., Tarakeshwar, P. \& Buttry, D. A. Electrochemical capture and release of carbon dioxide. ACS Energy Lett. 2, 454-461 (2017).

14. Stern, M. C., Simeon, F., Herzog, H. \& Hatton, T. A. Post-combustion carbon dioxide capture using electrochemically mediated amine regeneration. Energy Environ. Sci. 6, 2505-2517 (2013).

15. Aziz, M. J. \& Kwabi, D. G. pH swing cycle for $\mathrm{CO}_{2}$ capture electrochemically driven through proton-coupled electron transfer. Preprint at https://chemrxiv. org/articles/pH_Swing_Cycle_for_CO2_Capture_Electrochemically_ Driven_through_Proton-Coupled_Electron_Transfer/7853414 (2019).

16. Voskian, S. \& Hatton, T. A. Faradaic electro-swing reactive adsorption for $\mathrm{CO}_{2}$ capture. Energy Environ. Sci. 12, 3530-3547 (2019).

17. Scovazzo, P., Poshusta, J., DuBois, D., Koval, C. \& Noble, R. Electrochemical separation and concentration of $<1 \%$ carbon dioxide from nitrogen. $J$. Electrochem. Soc. 150, D91-D98 (2003).

18. Gurkan, B., Simeon, F. \& Hatton, T. A. Quinone reduction in ionic liquids for electrochemical $\mathrm{CO}_{2}$ separation. ACS Sustain. Chem. Eng. 3, 1394-1405 (2015).

19. Ranjan, R. et al. Reversible electrochemical trapping of carbon dioxide using 4,4'-bipyridine that does not require thermal activation. J. Phys. Chem. Lett. 6, 4943-4946 (2015).

20. Singh, P. et al. Electrochemical capture and release of carbon dioxide using a disulfide-thiocarbonate redox cycle. J. Am. Chem. Soc. 139, 1033-1036 (2017).

21. Han, C. et al. Organic quinones towards advanced electrochemical energy storage: recent advances and challenges. J. Mater. Chem. A 7, 23378-23415 (2019).

22. Huskinson, B. et al. A metal-free organic-inorganic aqueous flow battery. Nature 505, 195-198 (2014).

23. Mizen, M. B. \& Wrighton, M. S. Reductive addition of $\mathrm{CO}_{2}$ to 9,10 phenanthrenequinone. J. Electrochem. Soc. 136, 941-946 (1989).

24. Apaydin, D. H., Głowacki, E. D., Portenkirchner, E. \& Sariciftci, N. S. Direct electrochemical capture and release of carbon dioxide using an industrial organic pigment: quinacridone. Angew. Chem. Int. Ed. 53, 6819-6822 (2014).

25. Wielend, D., Apaydin, D. H. \& Sariciftci, N. S. Anthraquinone thin-film electrodes for reversible $\mathrm{CO}_{2}$ capture and release. J. Mater. Chem. A 6, 15095-15101 (2018).

26. Suo, L. et al. "Water-in-salt" electrolyte enables high-voltage aqueous lithiumion chemistries. Science 350, 938-943 (2015).

27. Simpson, T. C. \& Durand, R. R. Jr Reactivity of carbon dioxide with quinones. Electrochim. Acta 35, 1399-1403 (1990).

28. Gupta, N. \& Linschitz, H. Hydrogen-bonding and protonation effects in electrochemistry of quinones in aprotic solvents. J. Am. Chem. Soc. 119, 6384-6391 (1997).

29. Fujinaga, T., Izutsu, K. \& Nomura, T. Effect of metal ions on the polarographic reduction of organic compounds in dipolar arrotic solvents. $J$. Electroanal. Chem. Interf. Electrochem. 29, 203-209 (1971).

30. Wang, F. et al. Highly reversible zinc metal anode for aqueous batteries. Nat. Mater. 17, 543-549 (2018).

31. Yamada, Y., Wang, J., Ko, S., Watanabe, E. \& Yamada, A. Advances and issues in developing salt-concentrated battery electrolytes. Nat. Energy 4, 269-280 (2019).

32. Chen, S. et al. High-voltage lithium-metal batteries enabled by localized highconcentration electrolytes. Adv. Mater. 30, 1706102 (2018).

33. Nagaoka, T., Nishii, N., Fujii, K. \& Ogura, K. Mechanisms of reductive addition of $\mathrm{CO}_{2}$ to quinones in acetonitrile. J. Electroanal. Chem. $\mathbf{3 2 2}$, 383-389 (1992).
34. Yamamoto, T. \& Etori, H. Poly(anthraquinone)s having a.pi.-conjugation system along the main chain. synthesis by organometallic polycondensation, redox behavior, and optical properties. Macromolecules 28, 3371-3379 (1995).

35. Song, Z. et al. Polyanthraquinone as a reliable organic electrode for stable and fast lithium storage. Angew. Chem. Int. Ed. 54, 13947-13951 (2015).

36. Yin, W., Grimaud, A., Azcarate, I., Yang, C. \& Tarascon, J. -M. Electrochemical reduction of $\mathrm{CO}_{2}$ mediated by quinone derivatives: implication for Li-CO $\mathrm{CO}_{2}$ battery. J. Phys. Chem. C 122, 6546-6554 (2018).

37. Gavish, N. \& Promislow, K. Dependence of the dielectric constant of electrolyte solutions on ionic concentration: a microfield approach. Phys. Rev. E 94, 012611 (2016).

38. Phadke, S., Cao, M. \& Anouti, M. Approaches to electrolyte solvent selection for poly-anthraquinone sulfide organic electrode material. ChemSusChem 11, 965-974 (2018).

39. Luo, J. -Y., Cui, W. -J., He, P. \& Xia, Y. -Y. Raising the cycling stability of aqueous lithium-ion batteries by eliminating oxygen in the electrolyte. Nat. Chem. 2, 760-765 (2010).

40. Dong, Q. et al. Cathodically stable $\mathrm{Li}-\mathrm{O}_{2}$ battery operations using water-in-salt electrolyte. Chem 4, 1345-1358 (2018)

41. Weekes, D. M., Salvatore, D. A., Reyes, A., Huang, A. \& Berlinguette, C. P. Electrolytic $\mathrm{CO}_{2}$ reduction in a flow cell. Acc. Chem. Res. 51, 910-918 (2018)

42. Williams, K. et al. Protecting effect of mass transport during electrochemical reduction of oxygenated carbon dioxide feedstocks. Sustain. Energy Fuels 3, 1225-1232 (2019)

43. Metz, B., Davidson, O., De Coninck, H., Loos, M. \& Meyer, L. Carbon Dioxide Capture and Storage: Special Report of the Intergovernmental Panel on Climate Change (Cambridge University Press, 2005).

44. Wang, M., Hariharan, S., Shaw, R. A. \& Hatton, T. A. Energetics of electrochemically mediated amine regeneration process for flue gas $\mathrm{CO}_{2}$ capture. Int. J. Greenh. Gas. Con. 82, 48-58 (2019).

\section{Acknowledgements}

The authors thank Dr. Sahag Voskian for his help on quinone material synthesis. The authors would like to acknowledge Dr. David Calabro and Dr. Sophie Liu from the Corporate Strategic Research Laboratory of the ExxonMobil Research and Engineering Company for helpful discussions. The research was supported by ExxonMobil.

\section{Author contributions}

Y.L. and T.A.H. conceived the concept and designed the experiments. Y.L. carried out the experiments and H.-Z.Y. conducted the DFT calculations. T.A.H. and T.V.V. supervised the project. Y.L., K.M.D. and T.A.H. prepared the manuscript with input from all the other coauthors.

\section{Competing interests}

The authors declare no competing interests.

\section{Additional information}

Supplementary information is available for this paper at https://doi.org/10.1038/s41467 020-16150-7.

Correspondence and requests for materials should be addressed to T.A.H.

Peer review information Nature Communications thanks the anonymous reviewers for their contribution to the peer review of this work.

Reprints and permission information is available at http://www.nature.com/reprints

Publisher's note Springer Nature remains neutral with regard to jurisdictional claims in published maps and institutional affiliations.

Open Access This article is licensed under a Creative Commons Attribution 4.0 International License, which permits use, sharing, adaptation, distribution and reproduction in any medium or format, as long as you give appropriate credit to the original author(s) and the source, provide a link to the Creative Commons license, and indicate if changes were made. The images or other third party material in this article are included in the article's Creative Commons license, unles indicated otherwise in a credit line to the material. If material is not included in the article's Creative Commons license and your intended use is not permitted by statutory regulation or exceeds the permitted use, you will need to obtain permission directly from the copyright holder. To view a copy of this license, visit http://creativecommons.org/ licenses/by/4.0/.

(c) The Author(s) 2020 